\title{
The Genetic Deletion of 6q21 and PRDM1 and Clinical Implications in Extranodal NK/T Cell Lymphoma, Nasal Type
}

\author{
Li Liang, ${ }^{1}$ Zhang Zhang, ${ }^{1}$ Ying Wang, ${ }^{1}$ Lin Nong, ${ }^{1}$ Yalin Zheng, \\ Linlin Qu, ${ }^{1}$ Bo Zhang, ${ }^{2}$ and Ting $\mathrm{Li}^{1}$ \\ ${ }^{1}$ Department of Pathology, Peking University First Hospital, Beijing 100034, China \\ ${ }^{2}$ Department of Pathology, Peking University Health Science Center, Beijing 100191, China \\ Correspondence should be addressed to Ting Li; lixiaoting12@hotmail.com
}

Received 17 February 2015; Revised 4 June 2015; Accepted 10 June 2015

Academic Editor: Hesham H. Ali

Copyright (c) $2015 \mathrm{Li}$ Liang et al. This is an open access article distributed under the Creative Commons Attribution License, which permits unrestricted use, distribution, and reproduction in any medium, provided the original work is properly cited.

6q21 genetic deletion has been frequently detected in extranodal NK/T cell lymphoma, nasal type (EN-NK/T-NT), and PRDM1 is considered as candidate gene. However, direct detection of PRDM1 deletion has not been well documented. We investigated genetic alterations of 6q21 and PRDM1 in 43 cases of EN-NK/T-NT and cell lines by FISH. PRDM1 expression was evaluated by immunohistochemistry and Western blot. The correlation between genetic alteration and PRDM1 expression and the significance in clinic-pathologic were analyzed. Heterozygous deletion of 6q21 and/or PRDM1 was observed in 24 of 43 cases (55.81\%) of ENNK/T-NT including 16 cases (37.21\%) for 6q21 deletion and 19 cases (44.19\%) for PRDM1 deletion. Similarly, heterozygous codeletion of $6 \mathrm{q} 21$ and PRDM1 was identified in NK92 and NKL cells. The heterozygous deletion of 6q21 and/or PRDM1 was correlated with PRDM1 expression. However, genetic deletion of 6q21 and/or PRDM1 was not correlated with clinicopathological features of ENNK/T-NT, while PRDM1 expression showed positive effect on the outcome of patients as those as disease site, B symptom, and clinical stage. Thus, heterozygous deletion of 6q21 and/or PRDM1 was frequently detected in EN-NK/T-NT and correlated with downregulation of PRDM1. But the prognostic role of genetic deletion needs to be further evaluated in larger cohort.

\section{Introduction}

Extranodal NK/T cell lymphoma, nasal type (EN-NK/TNT), is featured by angiocentric and angiodestructive growth pattern characteristically correlated with progressive unrelenting ulceration and necrotic granulomatous alteration in midfacial tissues. Clinically, this lymphoma exhibits highly aggressive clinical course, poor outcome, and a predilection for East Asians and Central and South Americans [1]. Our recent investigation for 142 Northern Chinese patients with peripheral NK/T cell lymphomas revealed that ENNK/T-NT was the most prevalent subtype (38.0\%) [2]. The prognosis of EN-NK/T-NT is various, greatly depending on clinical factors, such as international prognostic index, stage, therapy modes, high proliferation rate, and primary tumour location $[3,4]$. However, previous reports for the prognostic significance of pathologic factors are distinct and even controversial. Although some putative oncogenic or molecular mechanisms have been incriminated to account for its high aggressiveness and pathogenesis, further elucidation of the genetic aberrations and pathological prognostic factors of this disease is needed [5-9].

Conventional cytogenetic studies in EN-NK/T-NT have showed chromosomal imbalances including deletions of $1 \mathrm{p}$, $6 \mathrm{q}, 11 \mathrm{q}, 13 \mathrm{q}$, and $17 \mathrm{p}$ and gains of $1 \mathrm{q}, 2 \mathrm{q}, 7 \mathrm{q}, 17 \mathrm{q}$, and $20 \mathrm{q}$ $[7,10,11]$, and recent studies reported that the deletion of chromosome 6q21 is the most frequent aberration in NK cell neoplasm and candidate genes in the region including PRDM1, FOXO3, ATG5, AIM1, and HACE1 have been investigated [7, 12-14]. Meanwhile, the inactivation of PRDM1 has been well documented and is consequently considered to be the putative candidate gene responsible for EN-NK/T-NT. 
In our recent research, loss of PRDM1 expression has been identified in a group of EN-NK/T-NT patients [15]. Nevertheless, up to date, concrete data concerning the analysis for genetic alteration of $6 \mathrm{q} 21$ and its putative tumor suppressor gene PRDM1 are still lacking.

In this study, we retrospectively investigated 70 cases of EN-NK/T-NT, carried out fluorescence in situ hybridization (FISH) test on formalin-fixed paraffin-embedded (FFPE) tumor specimens and NK/T lymphoma cell lines, clarified the deletion status of chromosome $6 \mathrm{q} 21$ and specific PRDM1 gene, and evaluated the clinical significances and prognostic factors.

\section{Materials and Methods}

2.1. Patients and Samples. 70 cases of EN-NK/T-NT were collected from archives of the Department of Pathology, Peking University First Hospital. The histological specimens of all cases were fixed in $10 \%$ buffered formalin and processed for routine paraffin-embedding. Histological sections with a thickness of $4 \mu \mathrm{m}$ were stained with hematoxylin and eosin and used for immunoperoxidase procedures. Diagnosis of EN-NK/T-NT was made on the basis of combined morphological and immunophenotypical findings (including positive CD56 and cytotoxic proteins) as well as EBV positivity as determined by in situ hybridization (ISH) with an EpsteinBarr virus-encoded small RNA (EBER-1) probe, according to WHO classification [16].

The gender ratio was 1.26 with 39 males and 31 females and ages ranging from 8 to 86 years (median 43 years). Follow-up data were available for 40 patients. The followup period was defined as the time from the date of initial diagnosis to the patient's death from any cause or last followup visit.

The study was approved by the ethics committee of Peking University First Hospital (no. 2013 [571]) and was performed according to ethics committee regulations and in accordance with the Declaration of Helsinki. The patient data were obtained from the medical record library through a doubleblind process and were analysed anonymously. There was no risk of conflict of interests for the patients.

2.2. Cell Culture. Three NK/T-cell lymphoma cell lines, YT [17], NK92 [18], NKL [19], and the human chronic myelogenous leukemia cell line K562 were used in the present study. YT and NKL cells were obtained from Beijing Hong Bokang Biological Technology (Beijing, China). NK92 and K562 cells were purchased from the Chinese Academy of Medical Sciences (Beijing, China). YT, NKL, and K562 cells were maintained in RPMI medium 1640 (Invitrogen, Carlsbad, CA, USA) with 10\% fetal bovine serum (Bio-Chrome, Germany) and were cultured in humidified $37^{\circ} \mathrm{C}$ incubator with $5 \% \mathrm{CO}_{2}$. NK92 cell was cultured in Alpha Minimum Essential medium (HyClone, UT, USA) with 12.5\% horse serum and $12.5 \%$ fetal bovine serum. The media of NK92 and NKL cells were supplemented with $100 \mathrm{U} / \mathrm{mL}$ human recombinant IL-2 (PeproTech, London, UK).
2.3. FISH. Probes of $6 \mathrm{q} 21, P R D M 1$ gene, and chromosome 6 (the centromere of chromosome 6) were purchased from Empire Genomics (New York, USA). For FFPE tumor specimens, dual-color FISH was performed according to the manufacturer's instructions. Briefly, tissue sections $(1.5 \mu \mathrm{m}$ thick) were deparaffinized in fresh xylene, rehydrated in $100 \%, 95 \%, 80 \%$, and 70\% ethanol, and air dried. After several washes in $2 \mathrm{x}$ SSC, the tissue sections were incubated in $\mathrm{dH}_{2} \mathrm{O}$ at $90^{\circ} \mathrm{C}$ for $30 \mathrm{~min}$ and incubated with protease $\mathrm{K}$ at $37^{\circ} \mathrm{C}$ for $1 \mathrm{~min}$. The slides were then rinsed in $2 \mathrm{x}$ SSC for $5 \mathrm{~min}$ and dehydrated in absolute ethanol and allowed to air dry. The slides were added with $10 \mu \mathrm{L}$ of hybridization mixture and denaturation for $4 \mathrm{~min}$ at $83^{\circ} \mathrm{C}$ and were incubated for $48 \mathrm{hr}$ in Hybridization Oven (ThermoBrite) at $37^{\circ} \mathrm{C}$. After being rinsed in $2 \mathrm{x}$ SSC/0.1\% NP-40, the slides were mounted with medium containing DAPI $(0.5 \mu \mathrm{g} / \mathrm{mL})$ for nuclear counterstaining. The cultured cells were affixed to glass slides using ThinPrep Cytology test, and $10 \mu \mathrm{L}$ of hybridization mixture was denaturized at $73^{\circ} \mathrm{C}$ for $5 \mathrm{~min}$ and hybridized at $37^{\circ} \mathrm{C}$ for $24 \mathrm{hr}$. For each of slides, 200 nuclei of cells were evaluated independently by two observers and the cut-off values for each probe were determined from three FFPE tonsil specimens and were defined as the mean copy number in tonsil plus three standard deviations for FFPE specimens. The cut-off baseline levels were $27.78 \%$ for $6 \mathrm{q} 21$ and $33.71 \%$ for $P R D M 1$ gene in specimens.

2.4. Immunohistochemistry (IHC). IHC staining was carried out using the DAKO EnVision detection kit (Dako, Glostrup, Denmark). Tissue sections were subjected to heat-induced antigen retrieval in EDTA buffer ( $\mathrm{pH} 9.0$ ). A panel of primary antibody including PRDM1 (clone C14A4, cell signaling, Beverly, MA, USA), granzyme B (clone 11F1, Novocastra, Newcastle upon Tyne, England), TIA-1 (clone TIA-1, Coulter, Hialeah, FL, USA), and CD56 (Clone UMAB83, Zhongshan, China) was utilized in our study.

A positive nuclear staining pattern was interpreted as representing PRDM1 immunoreactivity, while the cytoplasmic immunoreactivity for granzyme B or TIA-1 was considered as positive staining. Based on Garcia and Nie's investigations $[20,21]$, positive expression of PRDM1 was defined as nuclear staining in $10 \%$ or more of the tumour population and was semiquantitatively estimated as follows: negative (no positive cells or $<10 \%$ ), weak ( $10 \%$ to $\leq 50 \%$ positive cells), or strong ( $>50 \%$ to $100 \%$ positive cells). Tonsils sample was used as positive control for PRDM1 staining. For the negative control reactions, phosphate buffer saline (PBS) was used instead of the primary antibody.

2.5. Western Blot. Whole-cell lysates of YT, NK92, NKL, and K562 cells were separated in $10 \%$ sodium dodecyl sulfate polyacrylamide gel and were transferred to polyvinylidene difluoride (Millipore, MA, USA). After being blocked with $5 \%$ skim milk, the membrane was reacted with rabbit monoclonal antibody PRDM1 (PRDI-BF1) (1:1,000; Cell Signaling Technology, Beverly, MA) and $\beta$-actin $(1: 5,000$; Roche Applied Science, Indianapolis, USA). Secondary antibodies conjugated to Horseradish Peroxidase included anti-rabbit 
(1:5,000, Zhongshan, China) and anti-mouse $(1: 5,000$, Zhongshan, China). PRDM1 expression was quantified by densitometry and normalized with $\beta$-actin.

2.6. Statistical Analysis. The Spearman rank correlation coefficient test was utilized to correlate the expression of PRDM1 protein and deletion of $6 \mathrm{q} 21$ and/or PRDM1 gene. Treatment outcomes were measured by overall survival (OS) and failurefree survival (FFS). OS was calculated as the time from initial diagnosis to death from any cause or last followup. FFS was defined as the time from initial diagnosis to progression, relapse, or death from any cause. The estimates of FFS and OS were calculated using the Kaplan-Meier method and compared to log-rank tests. Multivariate analysis was conducted using the Cox proportional hazard model to define the independent prognostic factors for OS and FFS. Differences were considered statistically significant when the 2 -sided $P$ value was less than 0.05 . All analyses were performed using SPSS (Statistical Package for the Social Sciences) 13.0 software (Chicago, IL).

\section{Results}

3.1. Immunophenotyping of EN-NK/T-NT Cases. Immunohistochemically, all 70 cases showed positive staining for CD3 $\varepsilon$ and cytotoxic proteins (93.84\% for TIA-1, 92.06\% for granzyme B, and $86.15 \%$ for both), and 58 cases ( $82.86 \%$ ) were positive for CD56. ISH detection revealed positive staining for EBER in 63 cases $(90.00 \%)$ in moderate or strong intensitity. The remaining 7 EBER-negative cases expressed CD56 and cytotoxic granule proteins (TIA-1 and/or granzyme B). All 70 cases were reviewed and diagnosed by two experienced pathologists.

3.2. The Heterozygous Deletion of $6 q 21$ and PRDM1 in EN$N K / T-N T$. To disclose the cytogenetic alteration in ENNK/T-NT specimens, 43 FFPE specimens of EN-NK/T-NT were subjected to dual-color FISH for detection of $6 \mathrm{q} 21$ or PRDM1 gene deletion, respectively. We found that the cytogenetic alteration of $6 \mathrm{q} 21$ and $P R D M 1$ gene occurred in heterozygous deletion, while no homozygous deletion was found. As shown in Table 1, 24 of 43 EN-NK/T-NT cases (55.81\%) showed the heterozygous deletion of $6 \mathrm{q} 21$ and/or PRDM1, with 16 cases (37.21\%) for heterozygous deletion of $6 \mathrm{q} 21$ and 19 cases (44.19\%) for heterozygous deletion of PRDM1 gene. 11 EN-NK/T-NT cases presented the heterozygous codeletion of $6 \mathrm{q} 21$ and $P R D M 1$ gene. We also depicted that $5 \mathrm{EN}-\mathrm{NK} / \mathrm{T}-\mathrm{NT}$ cases showed only $6 \mathrm{q} 21$ heterozygous deletion (indicated by pound sign) and 8 cases presented only PRDM1 gene heterozygous deletion (indicated by asterisk) in Table 1 .

We found the significant positive correlation between 6q21 deletion and PRDM1 deletion by Spearman rank correlation coefficient test $(P=0.021, r=0.381)$. Representative FISH images of the heterozygous deletion of $6 \mathrm{q} 21$ and PRDM1 gene in EN-NK/T-NT cases were displayed in Figures 1 and 2.
TABLE 1: Heterozygous deletion of $6 \mathrm{q} 21$ and PRDM1 gene in NK/T cases.

\begin{tabular}{lcccc}
\hline & Heterozygous deletion & No deletion & Total & $P$ \\
\hline & 24 & 19 & 43 & $\mathbf{0 . 0 2 1}$ \\
6q21 & $11\left(5^{*}\right)$ & $19\left(8^{*}\right)$ & & \\
PRDM1 gene & $11\left(8^{*}\right)$ & $19\left(5^{*}\right)$ & & \\
\hline
\end{tabular}

$5^{\#}: 5$ cases only showing $6 \mathrm{q} 21$ heterozygous deletion.

$8^{*}: 8$ cases only showing PRDM1 gene heterozygous deletion.

TABLE 2: The comparison of PRDM1 expression with heterozygous deletion of $6 \mathrm{q} 21$ and PRDM1.

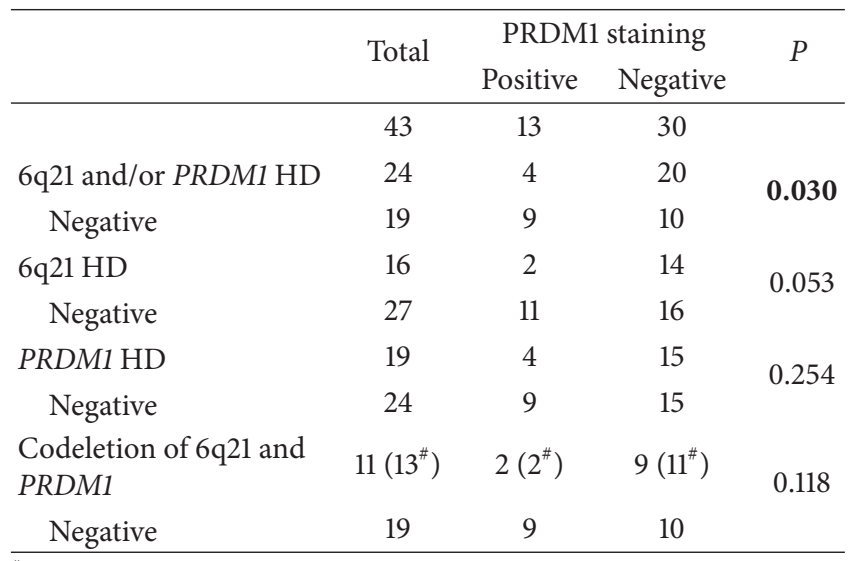

${ }^{\#}$ Cases with heterozygous deletion of either 6q21 or PRDM1 gene.

$\mathrm{HD}$, heterozygous deletion.

In addition, three NK/T lymphoma cell lines were also subjected to FISH detection. The heterozygous codeletion of 6q21 and PRDM1 was found in NK92 and NKL cells, but no deletion was found in YT cells and control cell line K562 (Figure 3(a)).

The finding proved that $6 \mathrm{q} 21$ deletion in EN-NK/T-NT was generally heterozygous and was commonly involved with PRDM1 gene.

3.3. The Correlation between PRDM1 Expression and the Genetic Deletion in EN-NK/T-NT. The correlation between PRDM1 expression and genetic deletion of $6 \mathrm{q} 21$ or PRDM1 was analyzed in 43 EN-NK/T-NT cases. PRDM1 positive staining was observed in 4 of 24 cases (16.67\%) with the deletion of $6 \mathrm{q} 21$ and/or PRDM1 in comparison with 9 of 19 cases (47.38\%) with no deletion (Table 2). Statistically, PRDM1 positive staining was significantly correlated with the heterogeneous deletion of $6 \mathrm{q} 21$ and/or PRDM1 $(P=$ $0.030, r=0.332)$. However, PRDM1 expression showed no correlation with the heterozygous deletion of PRDM1 alone $(P=0.254)$ or heterozygous codeletion of $6 \mathrm{q} 21$ and $P R D M 1$ $(P=0.118)$, except that PRDM1 staining reversely related to heterozygous deletion of 6q21 alone in marginal statistical value $(P=0.053)$. We also found that $13 \mathrm{EN}-\mathrm{NK} / \mathrm{T}-\mathrm{NT}$ cases showed the heterozygous deletion of either $6 \mathrm{q} 21$ or PRDM1 gene (indicated by pound sign) in Table 2, which was consistent with the data in Table 1. 


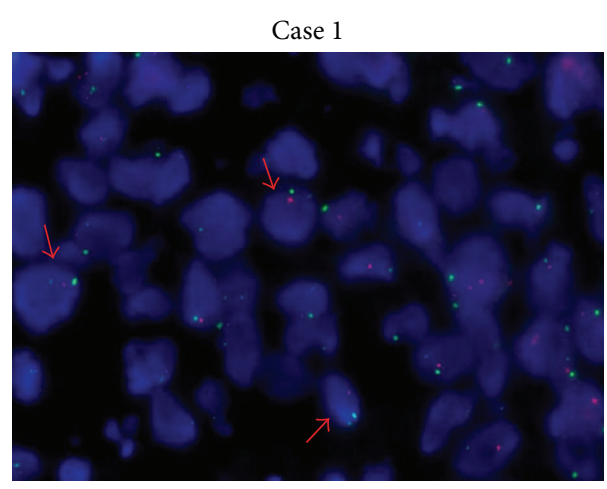

(a)

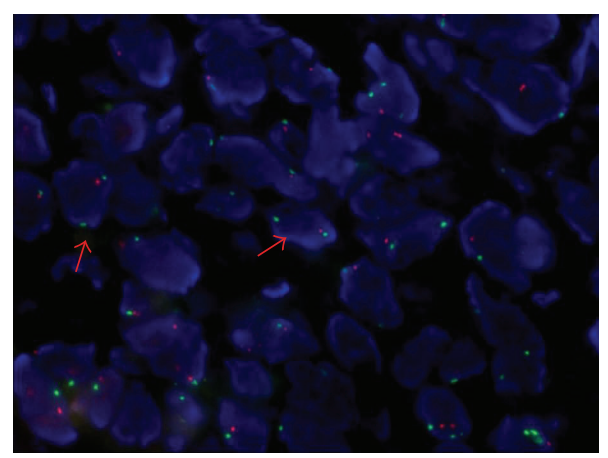

(b)

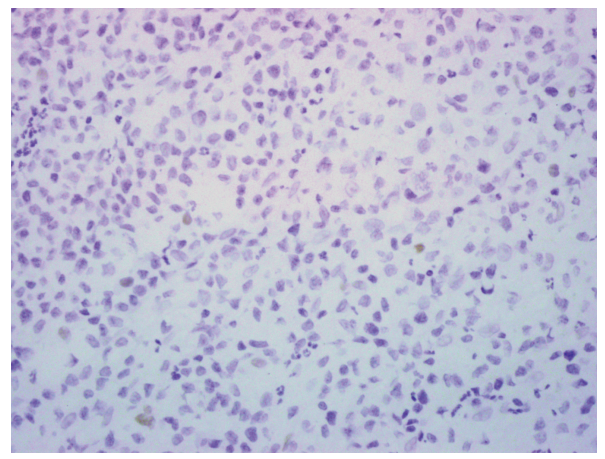

(c)

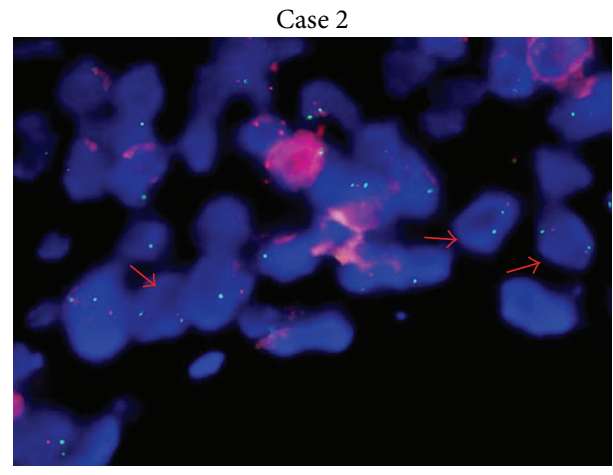

(d)

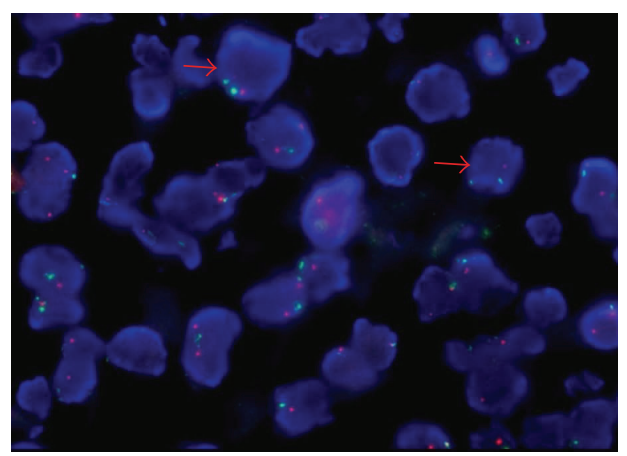

(e)

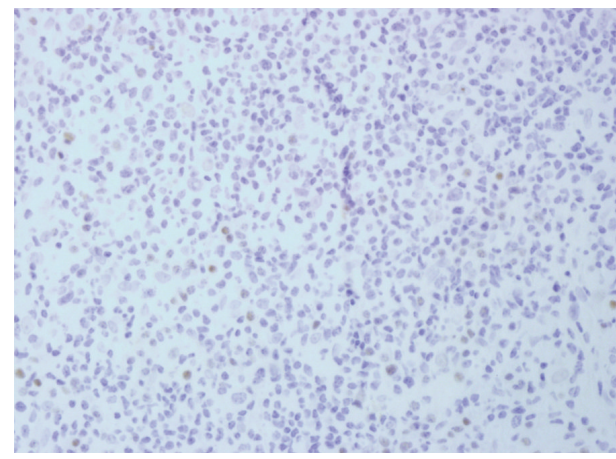

(f)

FIGURE 1: Identification of 6q21 and PRDM1 deletion by FISH and PRDM1 expression by immunostaining in EN-NK/T-NT cases. Dual-color FISH was performed with 6q21 probe or PRDM1 specific probe (labelled with 5-carboxyl-xrhodamine, red) and chromosome 6 centromere specific probe (labelled with 5 -fluorescein, green), respectively. Case 1, (a), (b), and (c): one representative case showed the heterozygous codeletion of 6q21 (a, two green and one red) and PRDM1 gene (b, two green and one red) and PRDM1 negative immunostaining (c). Case 2, (d), (e), and (f): another representative case with the heterozygous codeletion of 6q21 (d, two green and one red) and PRDM1 gene (e, two green and one red) and PRDM1 negative immunostaining (f). (a, b, d, and e at 1000x magnification; $c$ and $f$ at 400x magnification).

Our previous investigation has demonstrated that the downregulation of PRDM1 protein was common in ENNK/T-NT [15]. In this study, PRDM1 positive staining was observed in the nuclei of EN-NK/T-NT tumour cells and a quarter of EN-NK/T-NT cases (18/70, 25.71\%) exhibited weak expression of PRDM1 ( $10 \%$ to $\leq 50 \%$ stained cells) harbouring weak to moderate intensity, and the remaining 52 cases were negative in PRDM1 staining. The findings further identified the downregulation of PRDM1 protein in ENNK/T-NT cases.
With cultured cells, YT cells without deletion of 6q21 or PRDM1 showed strong PRDM1 expression in Western blot, but NK92 and NKL cells with the heterozygous deletion of 6q21 and PRDM1 showed weak expression (Figure 3(b)). However, control cell line K562 without 6q21 deletion or PRDM1 deletion lacked PRDM1 expression.

These findings were in agreement with what we have found in EN-NK/T-NT specimens, further demonstrating that PRDM1 expression may be associated with the heterozygous deletions of 6q21 and PRDM1 gene. 


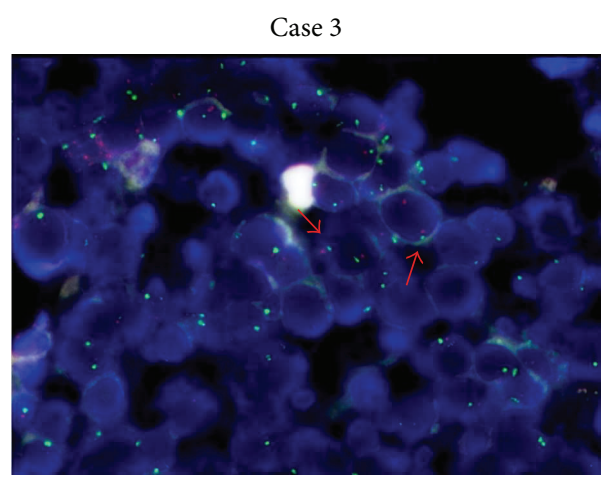

(a)

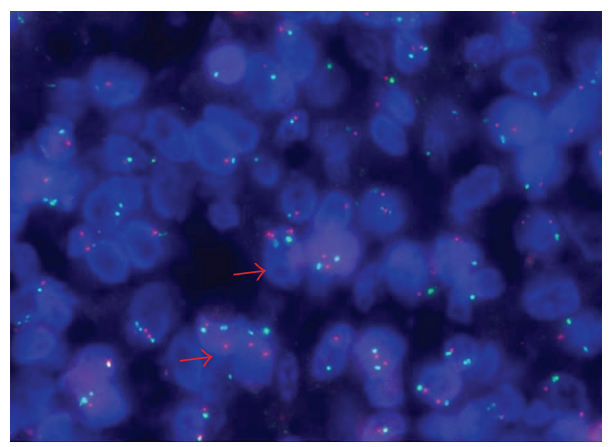

(b)

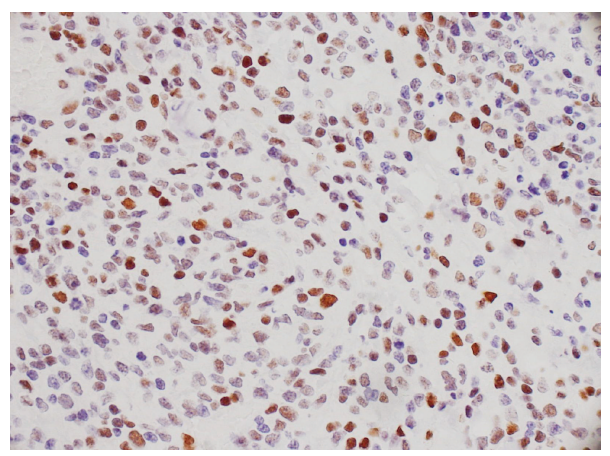

(c)

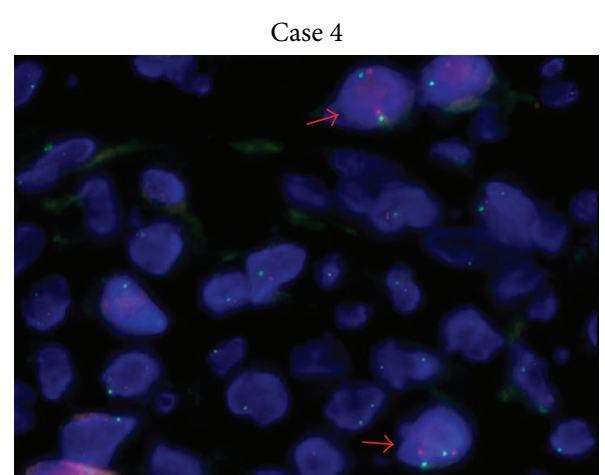

(d)

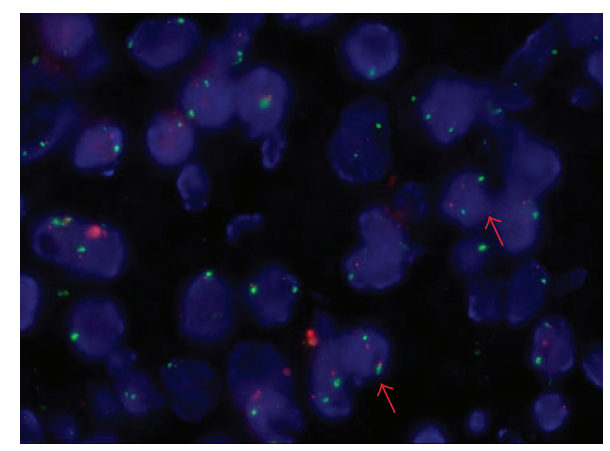

(e)

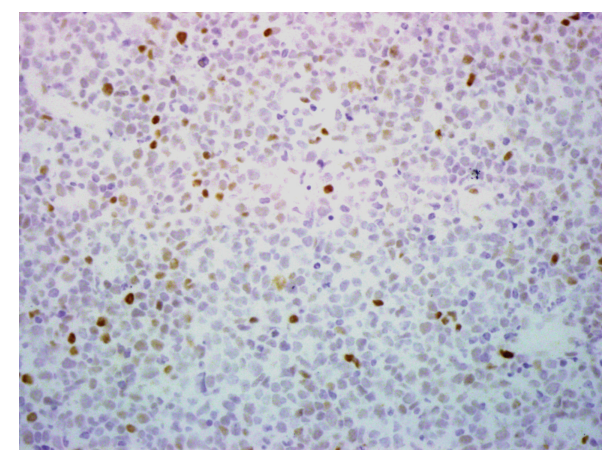

(f)

FIgure 2: Two representative EN-NK/T-NT cases without deletion of 6q21 or PRDM1 gene. Dual-color FISH was performed with 6q21 probe or PRDM1 specific probe (labelled with 5-carboxyl-xrhodamine, red) and chromosome 6 centromere specific probe (labelled with 5fluorescein, green), respectively. Case 3, (a), (b), and (c): one case without deletion of 6q21 (a, two green and two red) or PRDM1 gene (b, two green and two red) showed PRDM1 positive immunostaining (c). Case 4, (d), (e), and (f): another representative case without deletion of 6q21 (d, two green and two red) or PRDM1 gene (e, two green and two red) presented PRDM1 positive immunostaining (f). (a, b, d, and e at 1000x magnification; $\mathrm{c}$ and $\mathrm{f}$ at 400x magnification).

3.4. The Clinical Significance of Genetic Deletion and PRDM1 Expression. The clinicopathological significance of $6 \mathrm{q} 21$ deletion, specific PRDM1 gene deletion, and PRDM1 protein expression was analyzed from a follow-up cohort (40 cases) of EN-NK/T-NT cases. The median OS was 12.5 months (range, 1-120 months), and the median FFS was also 12.5 months (range, 1-87 months).

As shown in Table 3, 6q21 heterozygous deletion showed no significant association with sex, age, angiocentric infiltration, necrosis, site, EBER, B symptom, Ann arbor stage, and the outcome of patients $(P>0.05)$. Similar results were found between $P R D M 1$ heterozygous deletion and these clinical factors (Table 3). In addition, 6q21 heterozygous deletion was not significantly correlated with the OS and FFS of patients (Figure 4). Similarly, the status of specific PRDM1 gene showed no significant correlation with the OS and FFS (Figure 4). The clinical significance of the genetic deletion with either 6q21 and/or PRDM1 was also analysed. No significant correlation was found among them (Table 3, Figure 4). Furthermore, the clinical significance of 11 cases 
$6 \mathrm{q} 21$
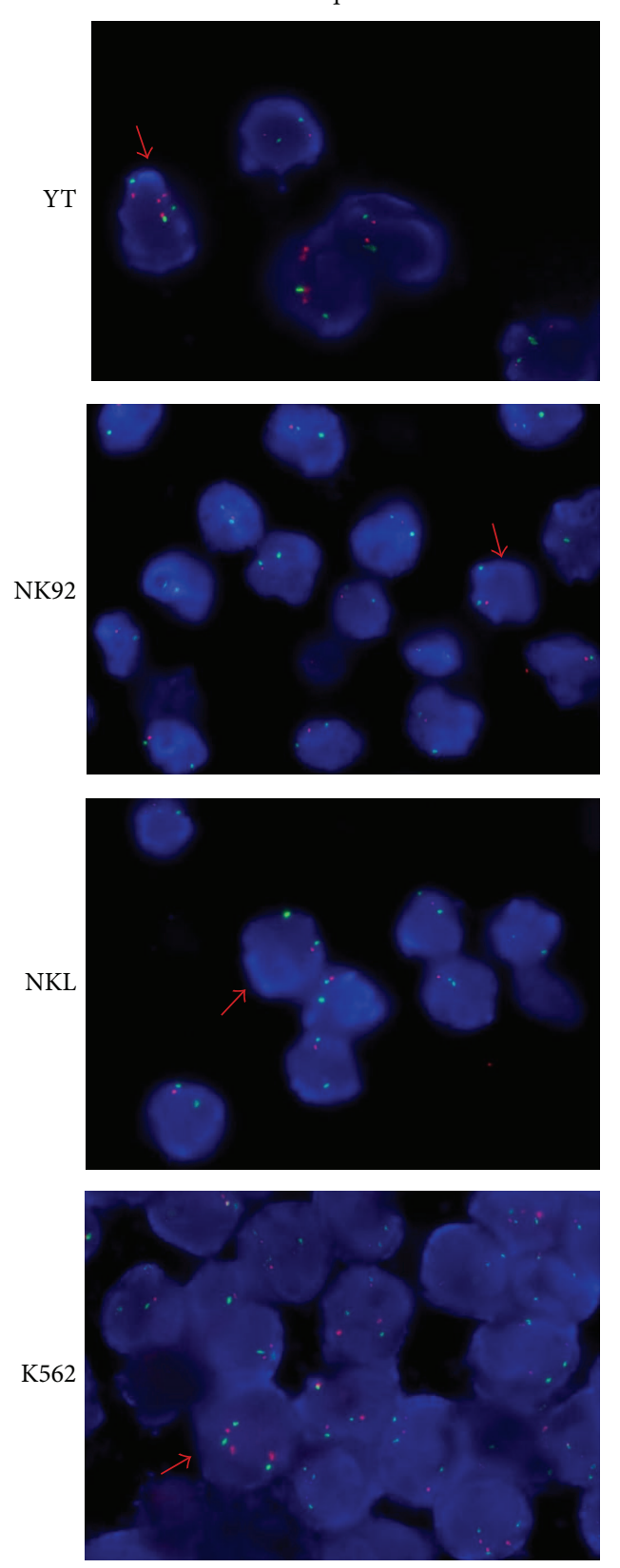

(a)
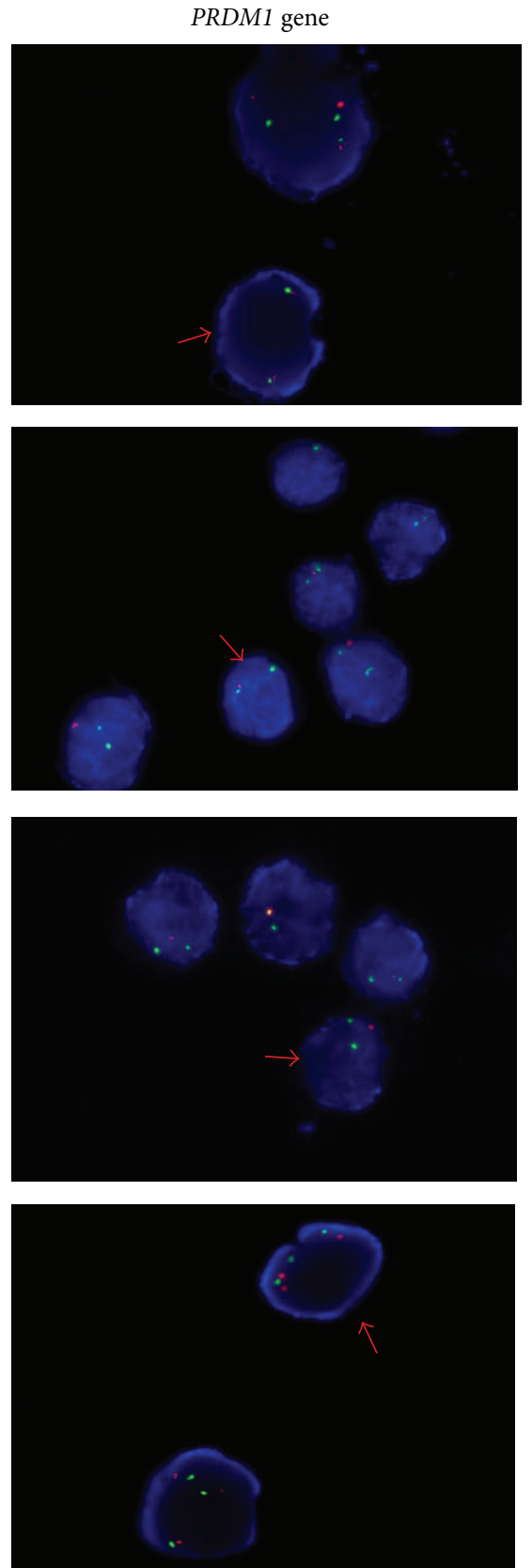

$\Delta 92^{\triangle}$

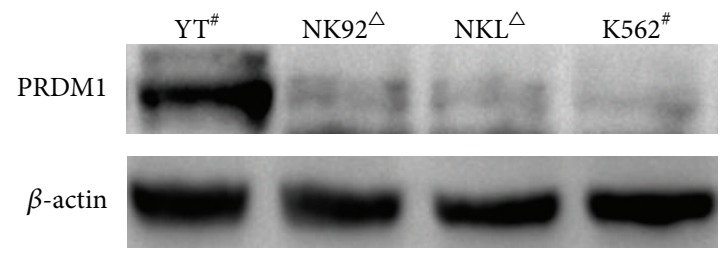

(b)

FIGURE 3: Identification of 6q21 and PRDM1 gene deletion by dual-color FISH and PRDM1 protein expression by Western blot in cell lines. (a) Dual-color FISH analysis was performed in NK/T cell lymphoma cell lines (YT, NK92, and NKL) and control cell line (K562, human chronic myelogenous leukemia cell) as described in Figure 1. YT cells with strong PRDM1 protein expression showed no deletion of 6q21 and PRDM1 gene, while NK92 and NKL cells with weak PRDM1 expression displayed the heterozygous codeletion of 6q21 and PRDM1. In addition, control cell line K562 lack of PRDM1 expression showed no deletion of 6q21 or PRDM1. All are shown at 1000x magnification. (b) Representative picture of PRDM1 protein expression by Western blot in YT, NK92, NKL, and K562 cells. " No deletion of $6 \mathrm{q} 21$ or PRDM1 gene. ${ }^{\triangle}$ The heterozygous codeletion of $6 \mathrm{q} 21$ and $P R D M 1$ gene. 

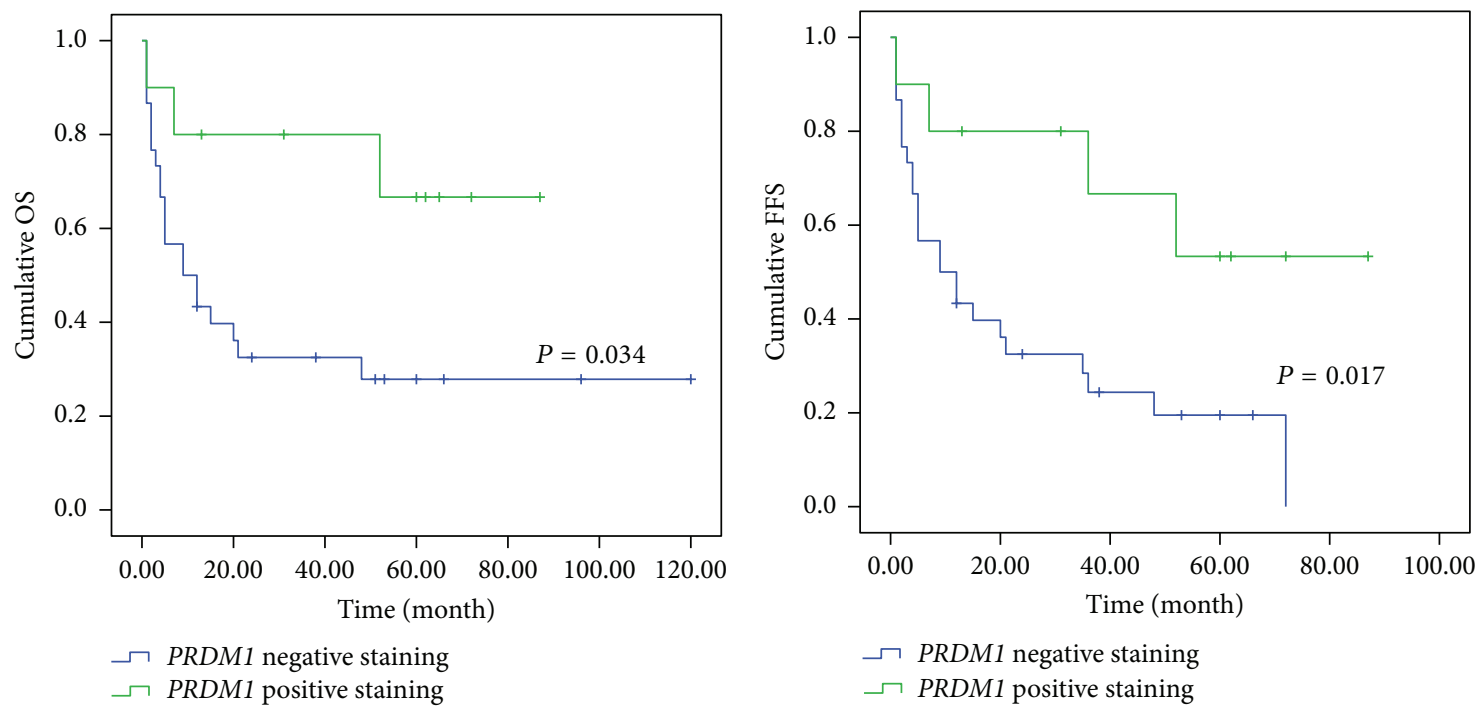

(a)

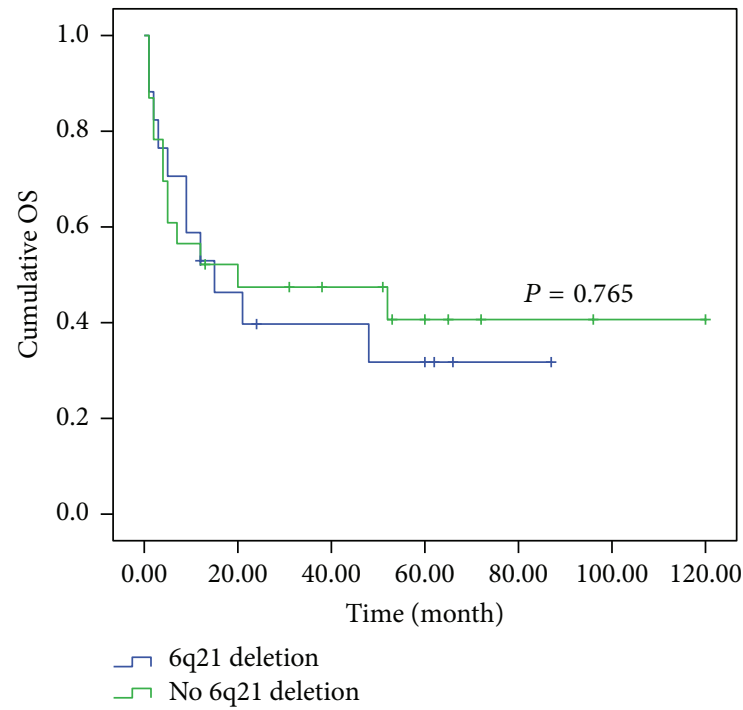

(c)

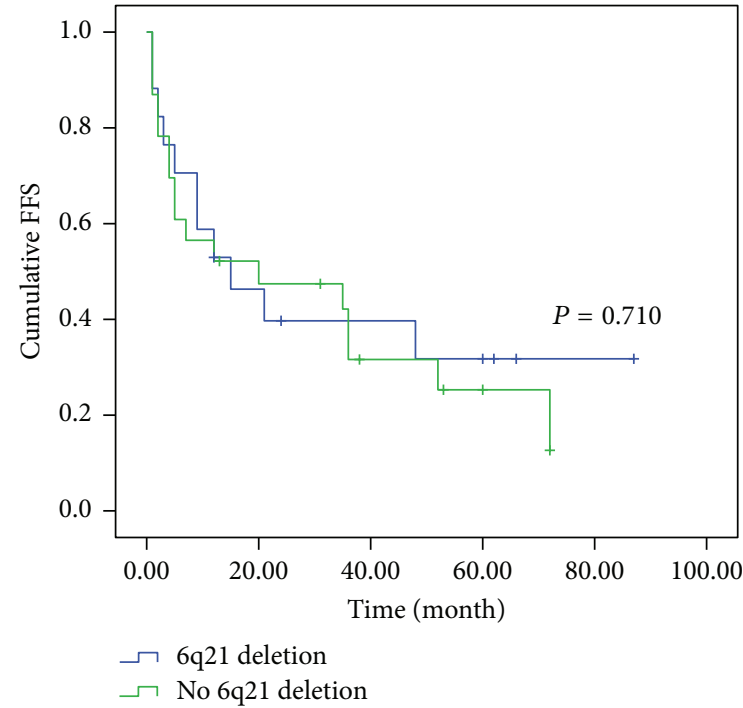

(d)

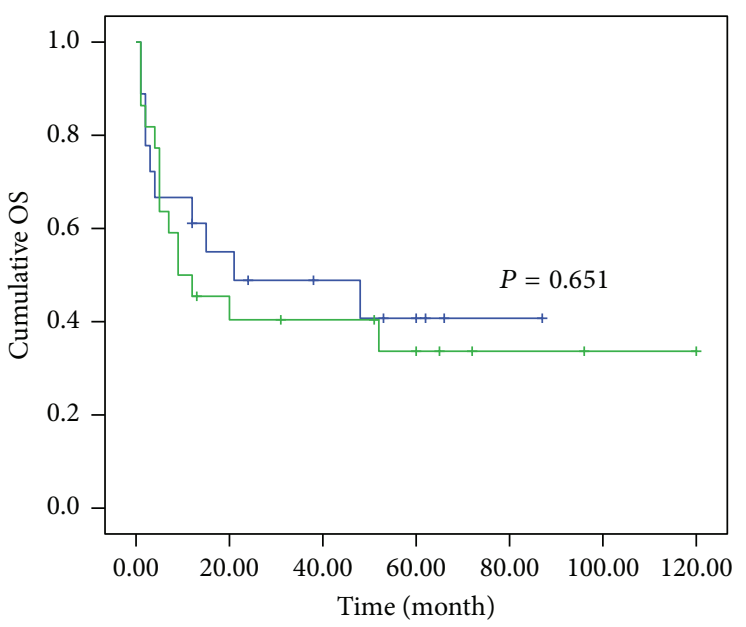

$\neg$ PRDM1 gene deletion

$\neg$ No PRDM1 gene deletion

(e)

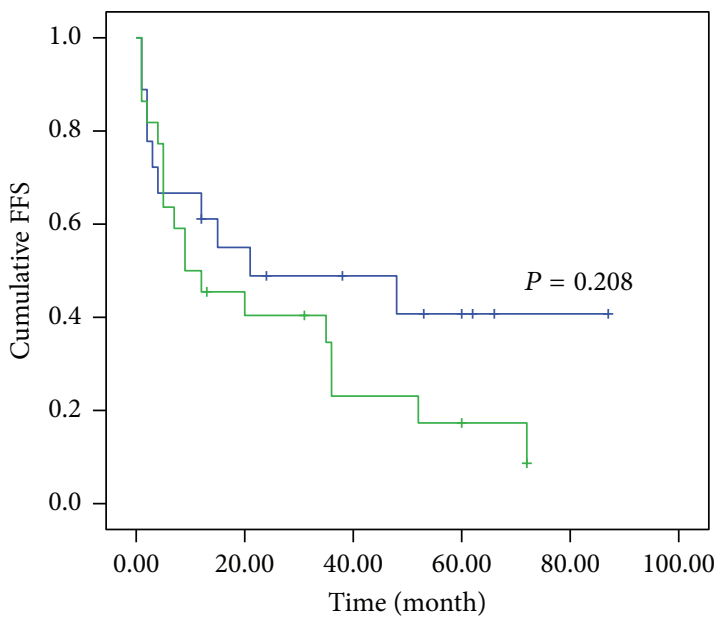

$\neg$ PRDM1 gene deletion

$\neg$ No PRDM1 gene deletion

(f)

Figure 4: Continued. 


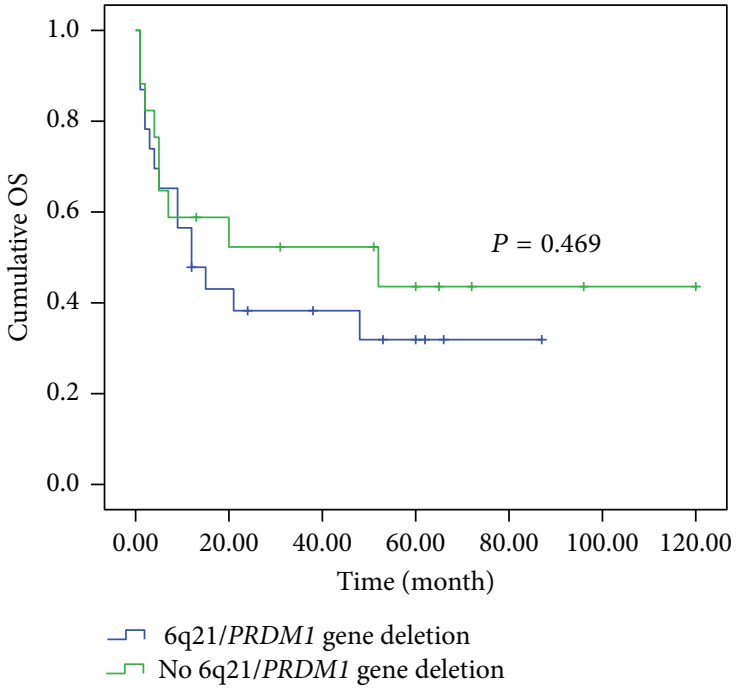

(g)

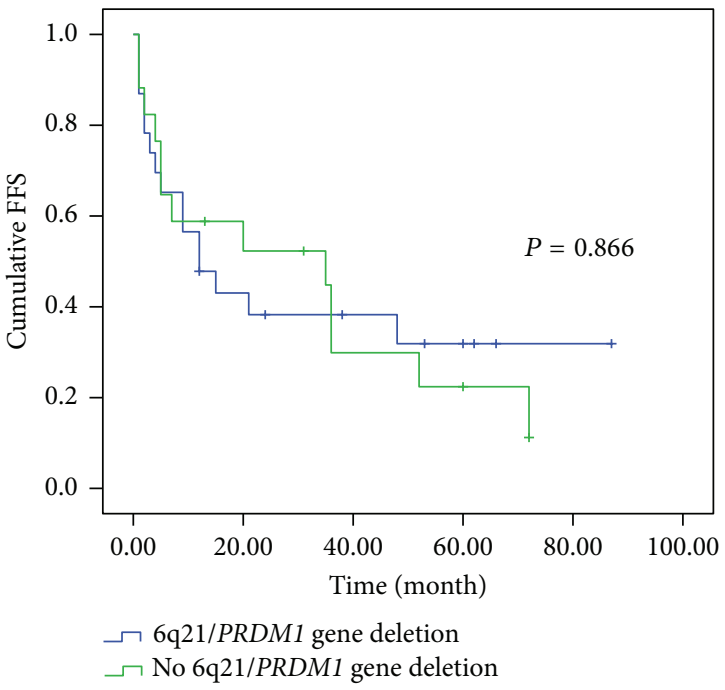

(h)

FIGURE 4: Kaplan-Meier survival analysis of PRDM1 immunostaining, 6q21 deletion, and PRDM1 deletion in follow-up cohort of 40 ENNK/T-NT cases. PRDM1 positive immunostaining predicted a favorable effect on overall survival (OS) (a, $P=0.034)$ and failure-free survival (FFS) (b, $P=0.017$ ) of EN-NK/T-NT patients. However, the status of 6q21 (c, d) and specific PRDM1 gene alone (e, f) showed no significant correlation with the OS and FFS as those of the deletion of $6 \mathrm{q} 21$ and/or specific PRDM1 gene ( $\mathrm{g}, P=0.469 ; \mathrm{h}, P=0.866$ ).

TABLE 3: The clinical significance of the heterozygous deletion of 6q21 and PRDM1 and deletion of 6q21 and PRDM1.

\begin{tabular}{|c|c|c|c|c|c|c|c|c|c|c|c|}
\hline & \multirow{2}{*}{$n$} & \multirow{2}{*}{ Percent } & \multicolumn{2}{|c|}{$6 q 21$} & \multirow{2}{*}{$P$} & \multicolumn{2}{|c|}{ PRDM1 } & \multirow{2}{*}{$P$} & \multicolumn{2}{|c|}{ 6q21/PRDM1 } & \multirow{2}{*}{$P$} \\
\hline & & & Deletion & No deletion & & Deletion & No deletion & & Deletion & No deletion & \\
\hline Patients & 43 & & & & & & & & & & \multirow{3}{*}{0.526} \\
\hline Male & 25 & 58.14 & 9 & 16 & \multirow{2}{*}{0.851} & 13 & 12 & \multirow{2}{*}{0.234} & 15 & 10 & \\
\hline Female & 18 & 41.86 & 7 & 11 & & 6 & 12 & & 9 & 9 & \\
\hline Age (year) & 43 & & & & & & & & & & \\
\hline$\leq 60$ & 32 & 74.42 & 13 & 19 & \multirow{2}{*}{0.441} & 13 & 19 & \multirow{2}{*}{0.435} & 18 & 14 & \multirow{2}{*}{0.924} \\
\hline$>60$ & 11 & 25.58 & 3 & 8 & & 6 & 5 & & 6 & 5 & \\
\hline Angiocentric infil & 43 & & & & & & & & & & \\
\hline With & 16 & 37.21 & 5 & 11 & \multirow{2}{*}{0.545} & 7 & 9 & \multirow{2}{*}{0.966} & 8 & 8 & \multirow{2}{*}{0.579} \\
\hline Without & 27 & 62.79 & 11 & 16 & & 12 & 15 & & 16 & 11 & \\
\hline Necrosis & 43 & & & & & & & & & & \\
\hline With & 34 & 79.07 & 13 & 21 & \multirow{2}{*}{0.793} & 16 & 18 & \multirow{2}{*}{0.473} & 20 & 14 & \multirow{2}{*}{0.452} \\
\hline Without & 9 & 20.93 & 3 & 6 & & 3 & 6 & & 4 & 5 & \\
\hline Site & 43 & & & & & & & & & & \\
\hline Nasal & 35 & 81.40 & 14 & 21 & \multirow{2}{*}{0.440} & 14 & 21 & \multirow{2}{*}{0.258} & 19 & 16 & \multirow{2}{*}{0.682} \\
\hline Extranasal & 8 & 18.60 & 2 & 6 & & 5 & 3 & & 5 & 3 & \\
\hline EBER & 43 & & & & & & & & & & \\
\hline Positive & 39 & 90.70 & 14 & 25 & \multirow{2}{*}{0.589} & 17 & 22 & \multirow{2}{*}{0.811} & 21 & 18 & \multirow{2}{*}{0.429} \\
\hline Negative & 4 & 9.30 & 2 & 2 & & 2 & 2 & & 3 & 1 & \\
\hline B symptom & 40 & & & & & & & & & & \\
\hline With & 20 & 50.00 & 5 & 15 & \multirow{2}{*}{0.055} & 6 & 14 & \multirow{2}{*}{0.059} & 9 & 11 & \multirow{2}{*}{0.115} \\
\hline Without & 20 & 50.00 & 11 & 9 & & 12 & 8 & & 14 & 6 & \\
\hline Ann arbor Stage & 43 & & & & & & & & & & \\
\hline I/II & 14 & 32.56 & 5 & 9 & 0.729 & 7 & 7 & 0.604 & 7 & 7 & 0.604 \\
\hline III/IV & 29 & 67.44 & 12 & 17 & & 12 & 17 & & 17 & 12 & \\
\hline Outcome & 40 & & & & & & & & & & \\
\hline Alive & 14 & 35.00 & 5 & 9 & 0.536 & 6 & 8 & 0.864 & 6 & 8 & 0.178 \\
\hline Dead & 26 & 65.00 & 12 & 14 & & 12 & 14 & & 17 & 9 & \\
\hline
\end{tabular}



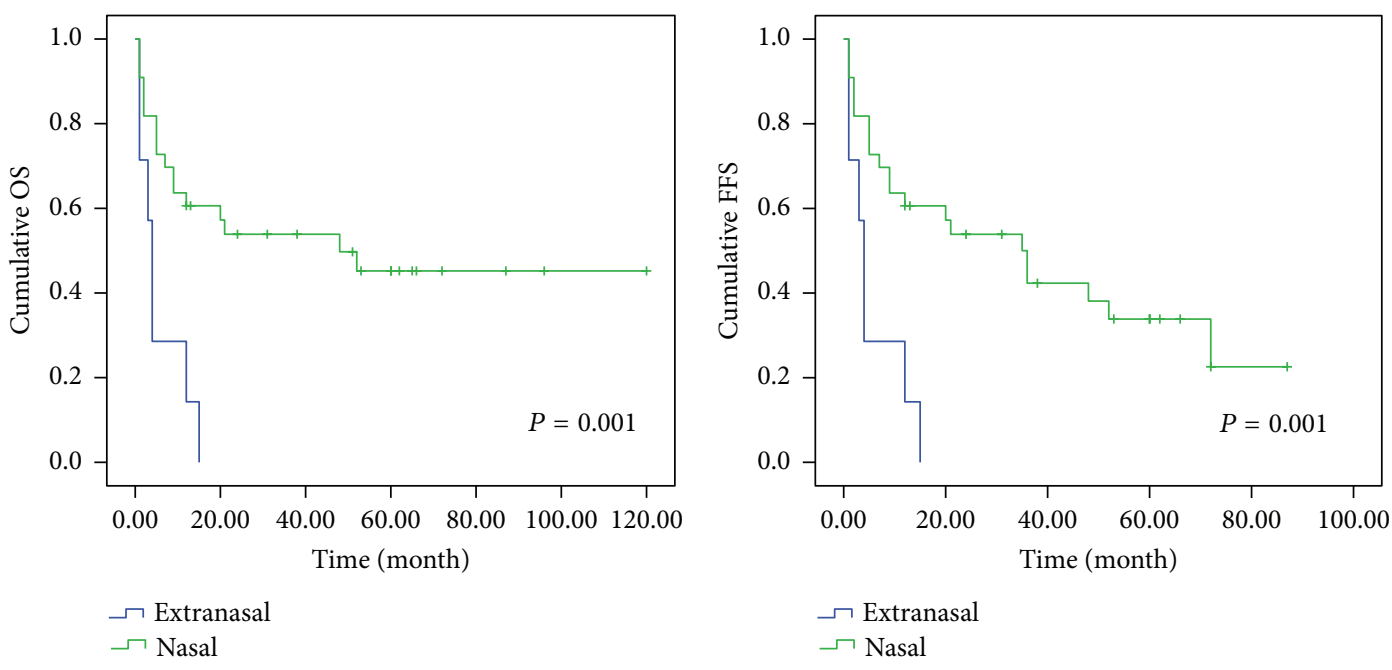

(a)
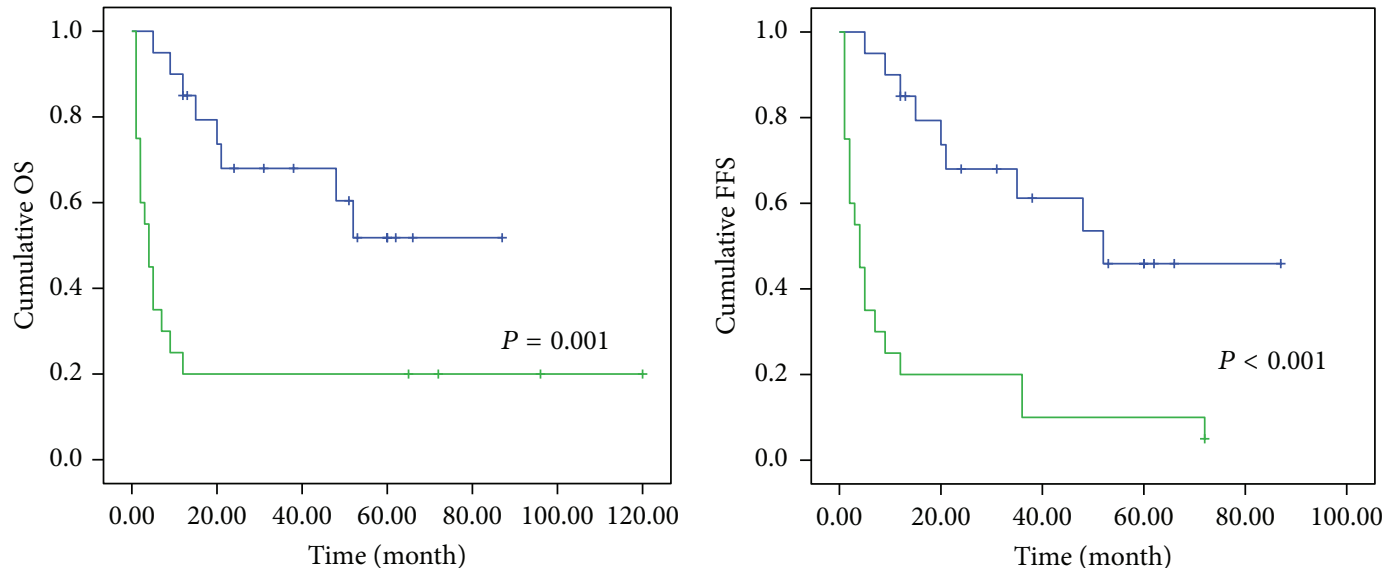

$\neg$ Absence of B symptom

$\neg$ Presence of B symptom

(c)

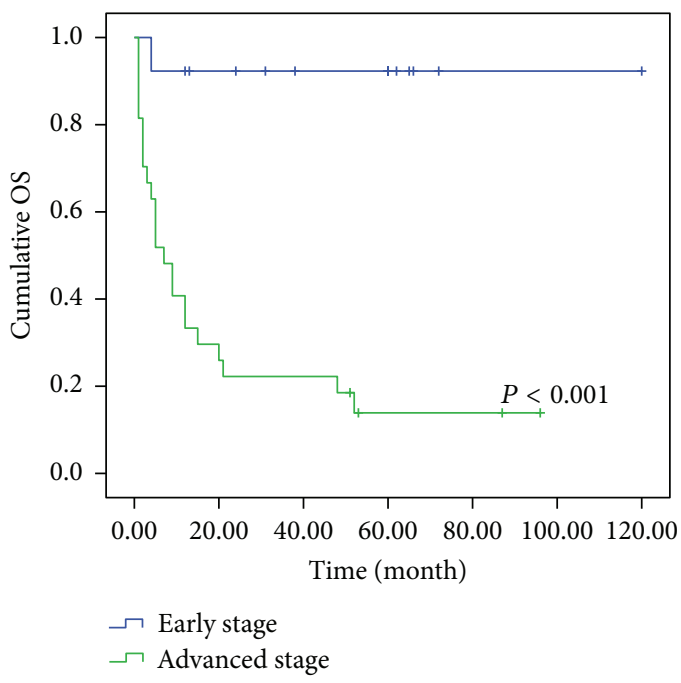

(e)

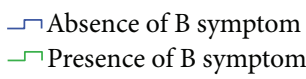

(d)

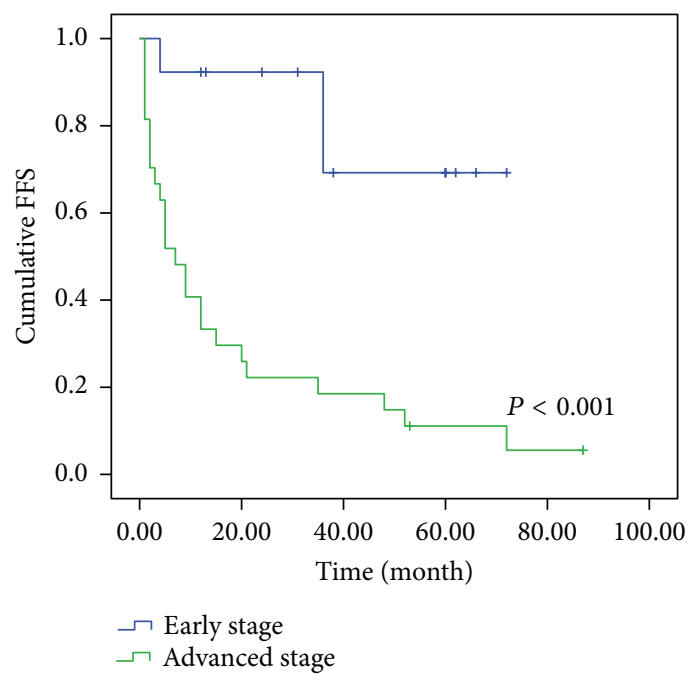

(f)

FIGURE 5: Kaplan-Meier survival analysis of disease site, B symptom, and clinical stage in 40 cases of EN-NK/T-NT. Statistically, EN-NK/TNT patients with extranasal disease present significant correlation with poorer OS (a, $P=0.001)$ and FFS $(\mathrm{b}, P=0.001)$. B symptom and late stage (III/IV) showed poorer OS and FFS (c, $P=0.001$;,$P<0.001$; e, $P<0.001$;,$P<0.001)$. 
TABLE 4: The clinical significance of PRDM1 expression.

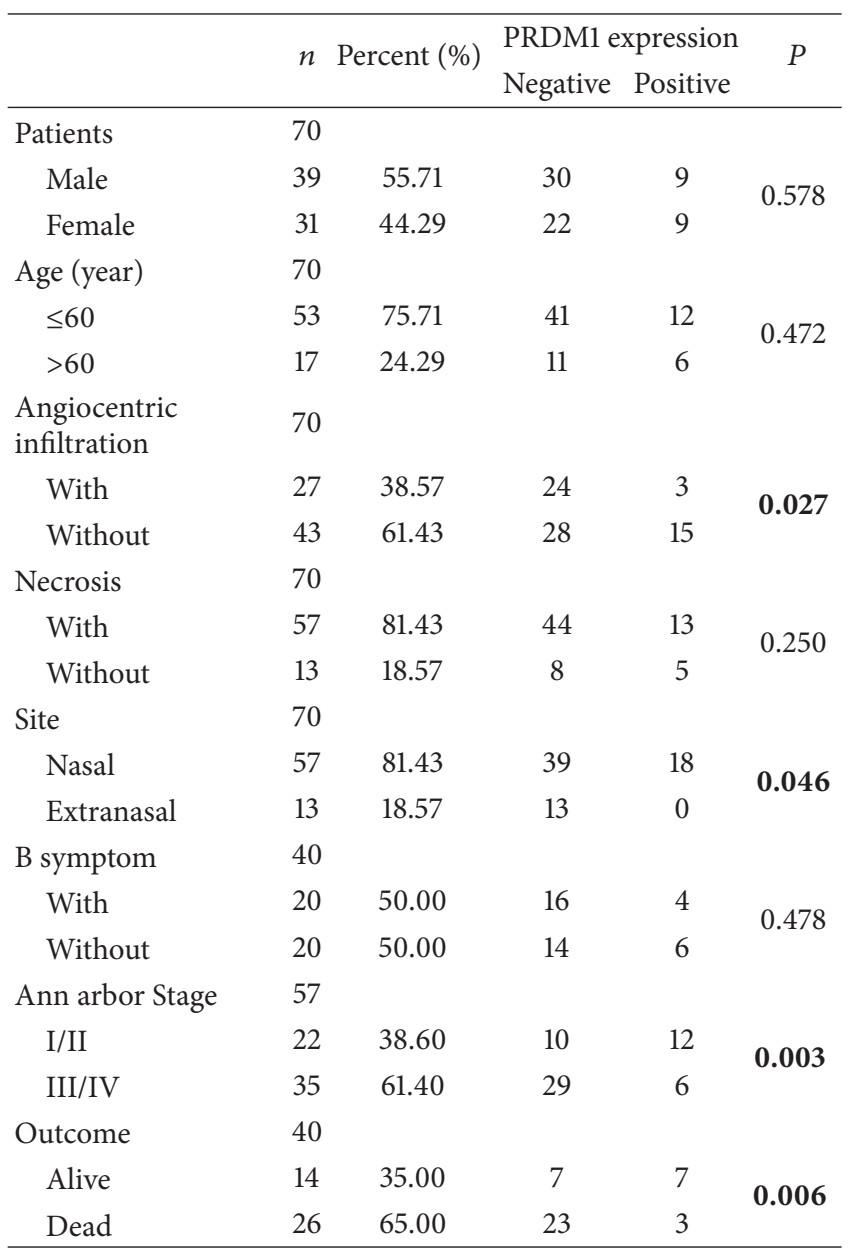

with codeletion of 6q21 and PRDM1 also showed no clinical significance (data not shown).

However, the expression of PRDM1 protein in specimens was decreased significantly with progression from early Ann Arbor stage (I/II stage) to advanced Ann Arbor stage (III/IV stage) $(P=0.003)$ (Table 4$)$. PRDM1 expression was significantly different between living and deceased patients $(P=0.006)$ (Table 4). Importantly, it was revealed that PRDM1-positive staining predicted a favorable effect on OS and FFS by Kaplan-Meier single-factor analysis and the logrank test (Figure $4, P=0.034, P=0.017$ ). Histologically, angiocentric and angioinvasive infiltration and necrosis were also commonly seen in PRDM1 negative cases, of which 27 cases (38.57\%) presented angiocentric and angioinvasive infiltration, and 57 cases (81.43\%) displayed necrosis. Statistically, we found that PRDM1 positive immunostaining was reversely correlated with angiocentric infiltration $(P=0.027$, $r=-0.265$ ) by the Spearman rank correlation coefficient test but not with necrosis (Table 4).

We found that PRDM1 immunostaining may not be the independent predictive factor using univariate analysis; in contrary, patients with extranasal disease exhibited poorer OS and FFS than cases with nasal disease (Figure 5, $P=$ $0.001, P=0.001)$. Additionally, B symptom and late stage
(III/IV) were associated with poorer OS and FFS (Figure 5, $P=0.001, P<0.001 ; P<0.001, P<0.001)$. Importantly, our results demonstrated that disease site, B symptom, and clinical stage were independent predictive factors of ENNK/T-NT patients by multivariate Cox model analysis.

\section{Discussion}

The deletion of $6 \mathrm{q} 21$ has been identified as the common genetic aberration in NK/T cell lymphoma $(20-43 \%)[5,10$, $12]$, and the genes located in the region of $6 \mathrm{q} 21$, including POPDC3, PREP, PRDM1, ATG5, AIM1, HACE1, and FOXO3, were reasonably considered the affected candidates $[7,12,13]$. Since the downregulation of PRDM1 and FOXO3 has been clarified in cells and clinical specimens of EN-NK/T-NT, both are believed to be candidate genes involved in genomic deletion. However, these investigations were generally done by conventional cytogenetic analysis or genomic approach such as array-based comparative genomic hybridization (aCGH), and direct analysis in tumor cells has been rarely performed. In the described study, we simultaneously detected $6 \mathrm{q} 21$ and PRDM1 using FISH assay in the collection of 43 cases of EN-NK/T-NT, we clarified that genetic deletion of $6 \mathrm{q} 21$ and/or PRDM1 could be found in 55.81\% (24/43) of ENNK/T-NT cases, and genetic alteration was heterozygous. In addition, we also revealed a consistence between EN-NK/TNT specimens and in vitro NK/T lymphoma cell lines. Thus, FISH analysis represented a highly sensitive, time-effective, and reliable alternative for the detection of 6q21 and PRDM1 deletion and can be utilized in routine pathologic diagnosis.

Despite that codeletion could be found in nearly half of cases, single deletion of $6 \mathrm{q} 21$ or PRDM1 could be observed in some cases of EN-NK/T-NT. Similarly, Karube et al. [13] also observed that genomic deletion could vary in a large region spaning 6q15-22 at least in length of $1.5 \mathrm{Mb}$. It could be assumed that the deletion of $6 \mathrm{q} 21$ region should sequentially occur in development of EN-NK/T-NT. On the other hand, as we all know, besides $P R D M 1,6 \mathrm{q} 21$ region also contains POPDC3, PREP, ATG5, AIM1, HACE1, and FOXO3. It is possible that $6 \mathrm{q} 21$ deletion should also involve above genes. Actually, FOXO3 gene has been identified to be heterozygous loss in NKL cell lines reported by Karube et al. [13], in which $\mathrm{FOXO} 3$ expression proved to be downregulated and was also regarded as a tumor suppressor gene. Karube et al. [13] suggest that FOXO3 together with PRDM1 could be considered to play more important roles as tumor suppressor genes in NK/T cell lymphoma than the other candidate genes located on 6q21. Other reports also indicated that the expression of HACE1, ATG5, and AIM1 was decreased in NK/T cell lymphoma $[5,7,22]$, although the research is limited. Further studies will be needed to confirm the status of genetic alteration in this region.

As other previous reports, we also observed a discrepancy between the genetic alteration and PRDM1 staining. This could be credited to heterozygous deletion of PRDM1, in which the cells still have an undeleted allele. Thus, another mechanism is needed to explain the loss of PRDM1 expression. In fact, mutations of PRDM1 have been clarified in 
NK92 cells and some cases of EN-NK/T-NT, in which basesubstitution in Exon 5 (C951A) or Exon 4 (C864A) results in nonsense mutation to generate truncated PRDM1 [7]. Meanwhile, epigenetic mechanism for inactivation of PRDM1 such as DNA methylation and micro-RNA silencing has also been described $[12,23]$. Our previous study has revealed that the downregulation of PRDM1 protein is common and is associated with upregulated miR-223 in EN-NK/T-NT [15]. In this study, we further found that PRDM1 expression was lost in most EN-NK/T-NT cases (74.29\%) and that the downregulation of PRDM1 protein may be associated with the heterozygous deletion of $6 \mathrm{q} 21$ or PRDM1 gene. Thus, PRDM1 protein level could be determined by heterozygous deletion of one allele and inactivation of another allele through genomic mutations or epigenetic silencing. It is believed that more clear answer could be expected from analysis on expanded cases.

Our previous research showed that PRDM1 expression could predict significant effect on Ann Arbor stage, OS, and FFS. Notably, PRDM1 positive immunostaining was negatively correlated with angiocentric infiltration, which is the characteristic histology in EN-NK/T-NT. In contrast, the heterozygous deletion of PRDM1 or $6 \mathrm{q} 21$ showed no important clinical significance and prognostic value. This is probably caused by the limited cases of FISH analysis, and further investigation in expanded cohort could give a more clear answer.

Collectively, the heterozygous deletions of $6 \mathrm{q} 21$ and PRDM1 gene were identified in FFPE EN-NK/T-NT specimens and cell lines by FISH analysis and significantly correlated with downexpression of PRDM1, which could be used as a prognostic indicator in evaluation of EN-NK/T-NT as disease site, B symptom, and clinical stage.

\section{Conflict of Interests}

The authors declare that there is no conflict of interests regarding the publication of this paper.

\section{Acknowledgment}

This work was supported by the research grant 81470359 from National Natural Sciences Foundation of China, Beijing.

\section{References}

[1] K. Aozasa, T. Takakuwa, T. Hongyo, and W.-I. Yang, "Nasal NK/T-cell lymphoma: epidemiology and pathogenesis," International Journal of Hematology, vol. 87, no. 2, pp. 110-117, 2008.

[2] Y.-L. Ren, L. Nong, S. Zhang, J. Zhao, X.-M. Zhang, and T. $\mathrm{Li}$, "Analysis of 142 Northern Chinese patients with peripheral T/NK-cell lymphomas: subtype distribution, clinicopathologic features, and prognosis," The American Journal of Clinical Pathology, vol. 138, no. 3, pp. 435-447, 2012.

[3] H. Fang, J. Jin, W. Wang, S. Wang, L. Zhou, and Y. Li, "Prognostic factors and treatment outcomes for patients with stage II extranodal nasal-type natural killer/T-cell lymphoma of the upper aerodigestive tract," Leukemia \& Lymphoma, vol. 55, no. 8, pp. 1832-1837, 2014.
[4] W.-Y. Au, D. D. Weisenburger, T. Intragumtornchai et al., "Clinical differences between nasal and extranasal natural killer/Tcell lymphoma: a study of 136 cases from the International Peripheral T-Cell Lymphoma Project," Blood, vol. 113, no. 17, pp. 3931-3937, 2009.

[5] Y. Huang, A. de Reyniès, L. de Leval et al., "Gene expression profiling identifies emerging oncogenic pathways operating in extranodal NK/T-cell lymphoma, nasal type," Blood, vol. 115, no. 6, pp. 1226-1237, 2010.

[6] P. Coppo, V. Gouilleux-Gruart, Y. Huang et al., "STAT3 transcription factor is constitutively activated and is oncogenic in nasal-type NK/T-cell lymphoma," Leukemia, vol. 23, no. 9, pp. 1667-1678, 2009.

[7] J. Iqbal, C. Kucuk, R. J. deLeeuw et al., "Genomic analyses reveal global functional alterations that promote tumor growth and novel tumor suppressor genes in natural killer-cell malignancies," Leukemia, vol. 23, no. 6, pp. 1139-1151, 2009.

[8] S. Zhang, T. Li, B. Zhang, L. Nong, and K. Aozasa, "Transcription factors engaged in development of NK cells are commonly expressed in nasal NK/T-cell lymphomas," Human Pathology, vol. 42, no. 9, pp. 1319-1328, 2011.

[9] Y. Yamanaka, H. Tagawa, N. Takahashi et al., "Aberrant overexpression of microRNAs activate AKT signaling via downregulation of tumor suppressors in natural killer-cell lymphoma/leukemia," Blood, vol. 114, no. 15, pp. 3265-3275, 2009.

[10] Y. Nakashima, H. Tagawa, R. Suzuki et al., "Genome-wide arraybased comparative genomic hybridization of natural killer cell lymphoma/leukemia: different genomic alteration patterns of aggressive NK-cell leukemia and extranodal NK/T-cell lymphoma, nasal type," Genes Chromosomes and Cancer, vol. 44, no. 3, pp. 247-255, 2005.

[11] Y. H. Ko, K. E. Choi, J. H. Han, J. M. Kim, and H. J. Ree, "Comparative genomic hybridization study of nasal-type NK/T-cell lymphoma," Cytometry, vol. 46, no. 2, pp. 85-91, 2001.

[12] C. Küçük, J. Iqbal, X. Hu et al., "PRDM1 is a tumor suppressor gene in natural killer cell malignancies," Proceedings of the National Academy of Sciences of the United States of America, vol. 108, no. 50, pp. 20119-20124, 2011.

[13] K. Karube, M. Nakagawa, S. Tsuzuki et al., "Identification of FOXO3 and PRDM1 as tumor-suppressor gene candidates in NK-cell neoplasms by genomic and functional analyses," Blood, vol. 118, no. 12, pp. 3195-3204, 2011.

[14] J. Yoon and Y. H. Ko, "Deletion mapping of the long arm of chromosome 6 in peripheral T and NK cell lymphomas," Leukemia \& Lymphoma, vol. 44, no. 12, pp. 2077-2082, 2003.

[15] L. Liang, L. Nong, S. Zhang et al., "The downregulation of PRDM1/Blimp-1 is associated with aberrant expression of miR223 in extranodal NK/T-cell lymphoma, nasal type," Journal of Experimental \& Clinical Cancer Research, vol. 33, no. 1, article 7, 2014.

[16] L. Quintanilla-Martinez, J. K. C. Chan, J. A. Ferry, and S. C. Peh, "Extranodal NK/T-cell lymphoma, nasal type," in World Health Organization Classification of Tumors. WHO Classification of Tumors of Aematopoietic and Lymphoid Tissues, S. H. Swerdlow, Ed., pp. 285-288, IARC Press, Lyon, France, 2008.

[17] J. Yodoi, K. Teshigawara, T. Nikaido et al., “TCGF (IL 2)receptor inducing factor(s). I. Regulation of IL 2 receptor on a natural killer-like cell line (YT cells)," The Journal of Immunology, vol. 134, no. 3, pp. 1623-1630, 1985.

[18] J.-H. Gong, G. Maki, and H.-G. Klingemann, "Characterization of a human cell line (NK-92) with phenotypical and functional 
characteristics of activated natural killer cells," Leukemia, vol. 8 , no. 4, pp. 652-658, 1994.

[19] M. J. Robertson, K. J. Cochran, C. Cameron, J.-M. Le, R. Tantravahi, and J. Ritz, "Characterization of a cell line, NKL, derived from an aggressive human natural killer cell leukemia," Experimental Hematology, vol. 24, no. 3, pp. 406-415, 1996.

[20] J.-F. Garcia, G. Roncador, J.-F. García et al., "PRDM1/BLIMP-1 expression in multiple B and T-cell lymphoma," Haematologica, vol. 91, no. 4, pp. 467-474, 2006.

[21] K. Nie, M. Gomez, P. Landgraf et al., "MicroRNA-mediated down-regulation of PRDM1/Blimp-1 in Hodgkin/ReedSternberg cells: a potential pathogenetic lesion in Hodgkin lymphomas," The American Journal of Pathology, vol. 173, no. 1, pp. 242-252, 2008.

[22] C. Küçük, X. Hu, J. Iqbal et al., "HACE1 is a tumor suppressor gene candidate in natural killer cell neoplasms," The American Journal of Pathology, vol. 182, no. 1, pp. 49-55, 2013.

[23] S.-B. Ng, J. Yan, G. Huang et al., "Dysregulated microRNAs affect pathways and targets of biologic relevance in nasal-type natural killer/T-cell lymphoma," Blood, vol. 118, no. 18, pp. 49194929, 2011. 


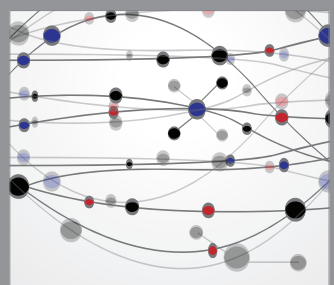

The Scientific World Journal
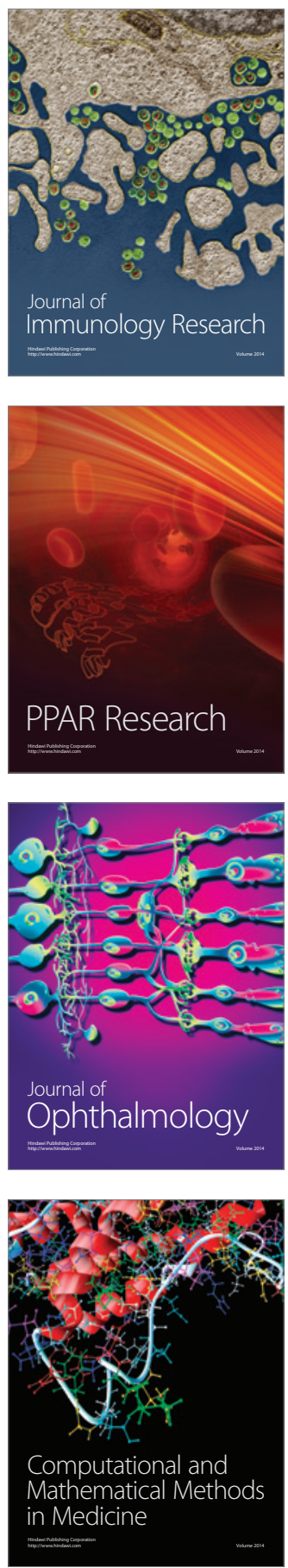

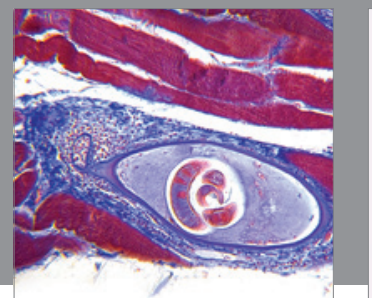

Gastroenterology

Research and Practice
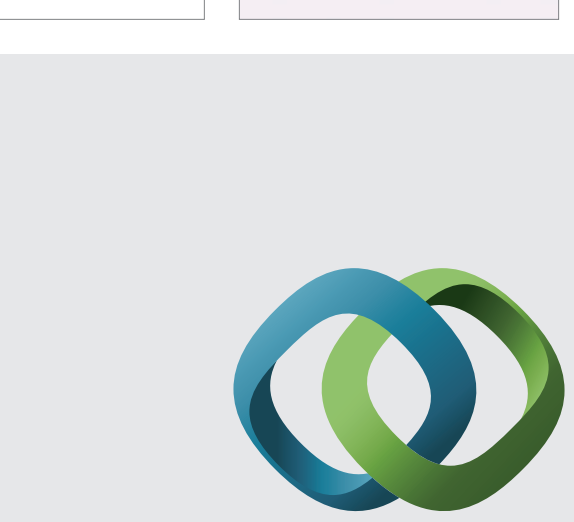

\section{Hindawi}

Submit your manuscripts at

http://www.hindawi.com
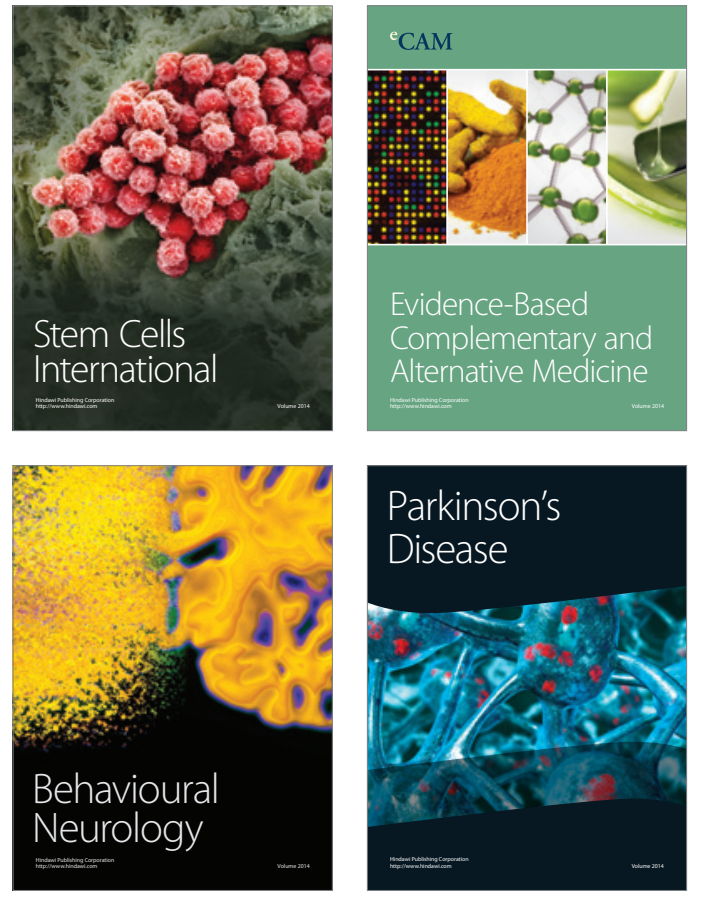
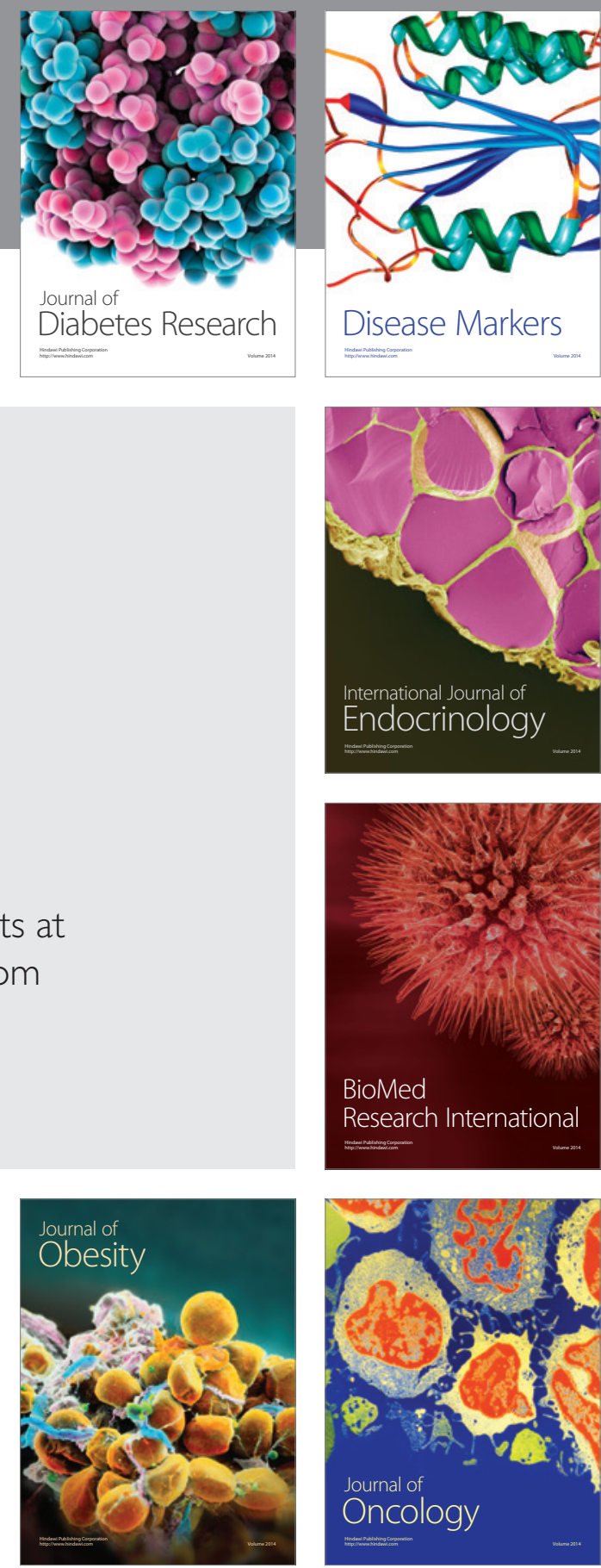

Disease Markers
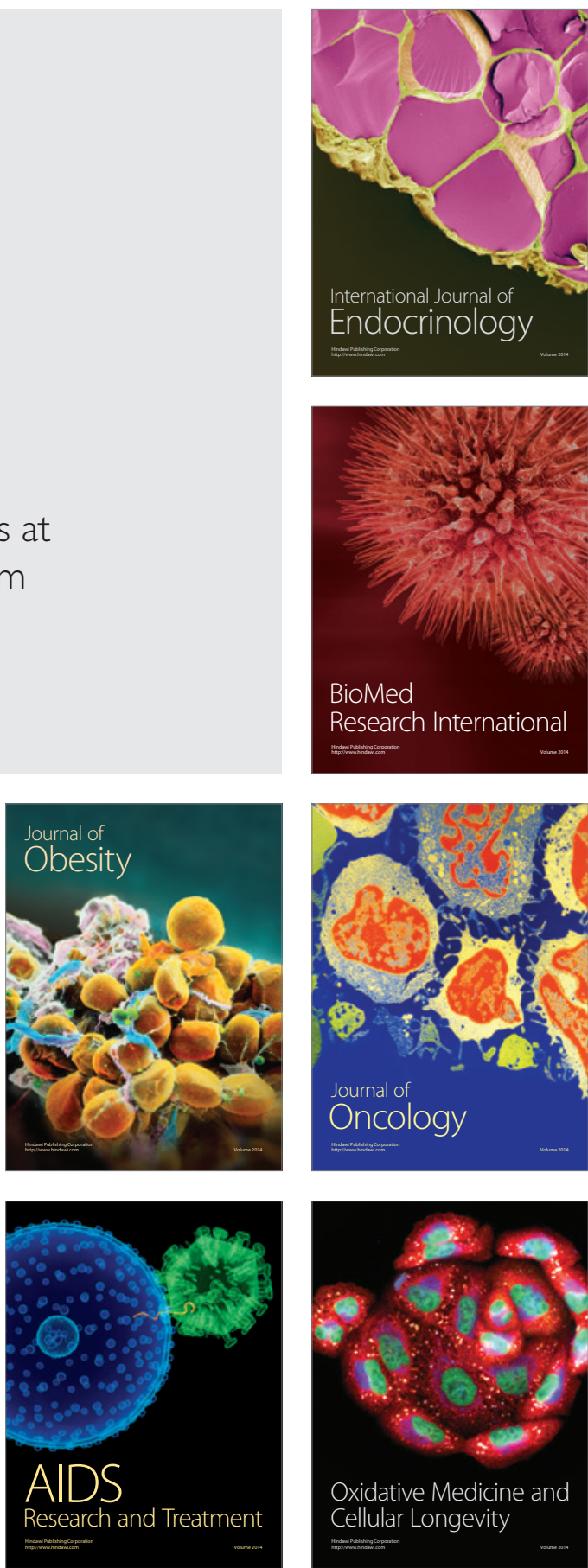